\title{
Impact of maternal and child dental anxiety on oral health-related quality of life of 5-6-year-old preschool children
}

\author{
Rashidah Esa ${ }^{1,2,3}$ (1), Marhazlinda Jamaludin ${ }^{2,3}$ (D) and Zamros Yuzadi Mohd Yusof f $^{2,3^{*}}$ (])
}

\begin{abstract}
Background: There is a lack of evidence with regards to the association between both maternal and child dental anxiety and the mother's perception of her child's oral health-related quality of life (COHRQoL). The aim of this study was to investigate the association of maternal and child dental anxiety with COHRQOL and the effect of demographic factors as moderators in this relationship. In addition, the association between child's dental caries experience and the COHRQoL was also assessed.
\end{abstract}

Methods: A cross-sectional study was conducted involving 1150, 5-6 year-old preschool children in Selangor, Malaysia. Mothers answered a questionnaire on socio-economic status, the Malay-Modified Dental Anxiety Scale to assess maternal dental anxiety, and the Malay-Early Childhood Oral Health Impact Scale to assess COHRQoL. Child's dental anxiety was assessed using the Malay-Modified Child Dental Anxiety Scale via a face-to-face interview prior to oral examination to assess dental caries. Data were analysed using structural equation modelling to assess the relationship between maternal and child dental anxiety and COHRQoL.

Results: Overall, complete data on 842 mother-child dyads were analysed. The mean scores of total ECOHIS, the child impacts section (CIS), and the family impacts section (FIS) were $17.7(\mathrm{SD}=4.9), 12.6(\mathrm{SD}=3.7)$, and $5.1(\mathrm{SD}=1.9)$, respectively. The mean dental anxiety scores for mothers and children were $11.8(S D=4.5)$ and $16.9(S D=4.3)$, respectively. Maternal dental anxiety was associated with the CIS $(b=0.08, p<0.001)$, the FIS $(b=0.01, p=0.001)$, and the total ECOHIS $(b=0.14, p<0.001)$. Maternal education level, income, urban/rural location, and kindergarten type were moderators to the relationship. In addition, there was also a significant relationship between child's dental caries experience and COHRQoL $(p<0.001)$.

Conclusions: Maternal dental anxiety and child's dental caries experience have significantly impacted the COHRQoL, the CIS, and the FIS domains. Demographic factors such as maternal education, income, urban/rural location, and kindergarten type acted as moderators that can strengthen or weaken the relationship between maternal dental anxiety and COHRQoL of 5-6-year-old preschool children.

Keywords: Dental anxiety, Oral health related quality of life, Dental caries, Children, Structural equation modelling

*Correspondence: zamros@um.edu.my

2 Department of Community Oral Health and Clinical Prevention, Faculty of Dentistry, University of Malaya, 50603 Kuala Lumpur, Malaysia

Full list of author information is available at the end of the article

\section{Background}

The term dental anxiety or fear has often been used synonymously in the literature. Dental anxiety can be described as a vague, unpleasant feeling accompanied by a premonition that something undesirable is about to happen, whereas dental fear is the anticipation of threat or harm elicited by an identifiable source [1-3]. Dental 
anxiety is a common problem worldwide where less than $20 \%$ of adults suffer from higher levels of dental anxiety and have had their lives affected $[4,5]$.

In Malaysia, the oral health programme for antenatal mothers was introduced in the early 1970s; however, only $39.2 \%$ of pregnant mothers utilised this service [6]. An earlier study revealed that among the barriers cited were 'being scared of treatment' and 'fear of seeing the dentist' [7]. Similarly, about $15 \%$ of the world's population avoids dental care to some extent due to fear [8-10]. Higher level of anxiety is not only associated with poorer oral health status but also causes psychosocial problems in children and adults $[6,11-14]$. While assisting highly anxious patients overcome their fear of dental treatment poses its own set of challenges, its success will no doubt result in the improvement of their oral health status, quality of life, and well-being $[15,16]$.

Besides dental anxiety, quality of life is also important as it helps us to understand the impact of dental problems and their treatment on patients' well-being [16-19]. The impact of oral health on quality of life is assessed using the oral health-related quality of life (OHRQoL) instruments [20]. Such instruments aim to measure the perceived impact of oral health on daily performances, psychosocial well-being, and social life. Assessing such impact in young children is essential because children with poor oral health will face future consequences not only on the development of permanent teeth, but also on their physical growth, weight, self-esteem, social life, and school achievement [21, 22]. Furthermore, as parents look after their young children, their dental problems frequently have extended consequences on the parents and family members who live with the child $[23,24]$.

A meta-analysis had reported a relationship between parental and child dental fear in children aged 8 years and below [25]. However, the strength of the relationship was dependent on the context of the dental visit and the types of measures used for assessing dental anxiety. At the same time, children whose mothers had moderate or high levels of dental anxiety were more likely to have untreated dental caries than children whose mothers had low dental anxiety [17, 26, 27]. In addition, many studies had reported that maternal dental anxiety, socioeconomic status, and oral health behaviours were also associated with poorer child's OHRQoL (COHRQoL) $[17,18,28,29]$. On the other hand, child dental anxiety was associated with child's dental caries [30], and child's dental caries was associated with COHRQoL [22]. However, there's a lack of evidence with regards to the association between both maternal and child dental anxiety and the mother's perception of her COHRQoL, especially in the local population. As a result, it was hypothesised that maternal and child dental anxiety have a significant impact on COHRQoL. Findings from this study will be important in designing effective interventions to alleviate dental anxiety in mother and child within the family and to improve the COHRQoL.

Therefore, the aim of this study was to investigate the association of maternal and child dental anxiety with COHRQoL and the effect of demographic factors as moderators in this relationship. In addition, the association between child's dental caries experience and the COHRQoL was also assessed.

\section{Methods}

This study, conducted in accordance with the 1964 Declaration of Helsinki, was approved by the Medical Ethics Committee, Faculty of Dentistry, University of Malaya [Reference: DF OP0809/0030(L)]. Permission to conduct the study was obtained from the Ministry of Education, Selangor State Education Department, kindergarten teachers, and parents of the children. Informed written consent was obtained from all participants included in the study prior to data collection.

This cross-sectional study was conducted in the Petaling (urban) and Hulu Langat (rural) districts in Selangor, Malaysia. Sample size calculation was based on the following parameters: design effect of 2.7 from a pilot study to account for the cluster sampling design, COHRQoL prevalence of $71.0 \%$ from a local study involving 5-6-year-old children [31], and a 35\% non-response rate resulting in a sample size of 1150 mother-child dyads. In terms of sample selection, two districts representing urban and rural areas were randomly chosen. In each district, kindergartens were stratified into private and public (government-run). Based on the student enrolment ratio, a total of 920 children were required from urban areas which included 230 and 690 children from public and private kindergartens, respectively. In rural areas, only 230 children were required which comprised of 115 children each from public and private kindergartens. A random number generator was used to choose the respective kindergartens.

The inclusion criteria were mothers who can speak and write in the Malay language and live with their 5-6-yearold children. Only healthy children were included. Children with chronic medical problems, on long-term medications, or who suffer from either physical or learning disabilities were excluded.

The questionnaire used in this study comprised of the mother's and child's socio-demographic information, the Malay version of the Modified Dental Anxiety Scale (Malay-MDAS) [32], the Malay version of the Modified Child Dental Anxiety Scale faces version $\left(\right.$ Malay-MCDAS ${ }_{\mathrm{f}}$ ) [33], and the Malay version of the Early Childhood Oral Health Impact Scale (Malay-ECOHIS) 
[31]. Family monthly incomes were categorised into low (MYR < 1500), moderate (MYR 1500 to 3500), and high income ( $>$ MYR 3500) in line with the minimum wage in Malaysia during the data collection period [34].

The Malay-MDAS was translated from the English MDAS [35, 36] to assess maternal dental anxiety. The Malay-MCDAS $\mathrm{f}_{\mathrm{f}}$ was translated from the English $\mathrm{MCDAS}_{\mathrm{f}}$ [37] to assess child's dental anxiety. The English $\mathrm{MCDAS}_{\mathrm{f}}$ was developed from the MCDAS $[38,39]$ where a faces rating scale was added to assess dental anxiety in young children. The Malay-ECOHIS was translated from the English ECOHIS that was developed and validated in the USA among 2-5-year-old children and their families [40]. In this study, the Malay-ECOHIS was used as a proxy-reported measure to assess oral impacts among preschool children in the Malaysian setting. It was validated for children up to 6 years old and therefore its use in this study was justified.

The Malay-MDAS has similar response options to the English MDAS, and the additional fifth item assesses anxiety when receiving a local anaesthetic injection. The response options are standardised to a five-point scale from "not anxious" to "extremely anxious" with the total score ranging from 5 to 25 . A score of 19 or more is regarded as extremely dentally anxious, equivalent to dental phobia [35]. In our study, higher Malay-MDAS scores indicated higher maternal dental anxiety levels.

The Malay-MCDAS $\mathrm{f}$ is a child-reported measure consisting of six questions about visiting the dentist and dental procedures. Each question is rated on a five-point rating scale ranging from "relaxed or not worried" to "very worried". Many studies have used either the mean or the median score as a cut-off point for dentally anxious [37, 41-46]; however, the use of this cut-off point may introduce bias in the conclusions, as the proportion of the population categorised as dentally anxious has been predetermined. In this study, the Malay-MCDAS $\mathrm{S}_{\mathrm{f}}$ scores ranged from 6 to 30 points where higher scores indicate higher child dental anxiety levels. The children's anxiety scores were categorised as low (6 to 10 points), moderate (11 to 20 points), or high (24 to 26 points) based on previous studies [41-43]. However, the child dental anxiety scores were used as a continuous variable in the Structural Equation Modelling (SEM) analysis.

The Malay-ECOHIS has 13 items in two main parts: the child impacts section (CIS) and the family impacts section (FIS). The CIS has 4 domains with 9 items: child symptoms (1 item), child function (4 items), child psychology ( 2 items), and child self-image/social interaction ( 2 items). The FIS has 2 domains with 4 items: parental distress ( 2 items) and family function ( 2 items). Each item is rated using five response options: $0=$ never, $1=$ hardly ever, $2=$ occasionally, $3=$ often, $4=$ very often, and
$5=$ don't know. The total score was obtained by summing the scores of the 13 items which ranges from 0 to $52(0$ to 36 for the CIS, 0 to 16 for the FIS). Items answered with 'don't know' responses were recoded as missing values. For up to two 'don't know' responses in the CIS and one in the FIS, the missing values were replaced by the mean score of the remaining items for that particular section. We excluded participants with three or more 'don't know' responses in the CIS or two or more 'don't know' responses in the FIS following the method of data scoring proposed in the original version [40]. In this study, higher Malay-ECOHIS scores indicated higher oral impacts and poorer OHRQoL. For the category of impact, response options 'never' or 'hardly ever' were categorised into 'no impact' while 'occasionally' to 'very often' were categorised into 'with impact'.

The self-administered questionnaire, patient information sheet, and consent form were distributed to the mothers by the teachers. The mothers returned the signed consent form and the completed parental questionnaire before the children were interviewed and underwent oral examination. Only children whose mothers provided written consent were included in the study. Children's dental anxiety was assessed via individual face-to-face interviews. Two trained dental surgery assistants and the main author (RE) conducted the interviews. The children were briefed on the response options of the Malay-MCDAS ${ }_{\mathrm{f}}$ faces scale before they were interviewed.

In terms of oral examination, four dental examiners underwent calibration in diagnosing caries at dental school. Dental caries of the primary teeth was assessed as decayed, missing, or filled teeth $(\mathrm{dmft})$. Caries was diagnosed as clinically detectable lesions in dentine (D3 level) without the use of a probe. The four dental examiners examined 20 children for caries and their findings were compared with that of a gold standard who was a paediatric dental specialist. Re-examination was conducted after one week. Kappa statistics were used to assess the inter- and intra-examiner reliability for caries in primary teeth. The results showed that the inter-examiner Kappa values for dental caries ranged from 0.76 to 0.79 , indicating good reliability while the intra-examiner Kappa values ranged from 0.65 to 1 , indicating moderate to very good reliability [47]. In the actual study, oral examinations were performed using a plane mouth mirror under natural light in the kindergarten. Following the oral examination, mothers were given brief advice on their child's dental caries status. Children with caries who required treatment were referred to a nearby dental clinic.

Data were analysed using the Statistical Package for Social Sciences (SPSS) Version 22 software (SPSS Inc., Chicago, IL, USA). Descriptive statistics (mean and 
standard deviation, frequency and percentage) were used to describe the socio-demographic data of the participants, the MDAS, the MCDAS , and the ECOHIS domains. Next, Structural Equation Modelling (SEM) was designed to determine the impact of maternal and child dental anxiety, and child dental caries on COHRQoL (Model 1). Model 2 was designed to test the impact of maternal and child dental anxiety, and child dental caries on COHRQoL in subconstructs (CIS and FIS) in order to examine which subconstruct will have more impact on COHRQoL. In addition, Model 3 was only to test the impact of moderators (demographic factors) on the relationship of maternal dental anxiety $\rightarrow$ COHRQoL as only maternal dental anxiety showed significant impact towards COHRQoL.

In this study, the intra-cluster correlation was not calculated in the sample due to the fact that the analysis using SEM has the flexibility to handle data involving complex sampling issues with cluster samples in multistage sampling [48]. Furthermore, the sample size of the study was large enough that the assumption of normality of data was achieved.

The statistical package used was Analysis of Moment Structures Version 22 (AMOS V 22) by using Maximum Likelihood Estimation. The model fitness indices accessed indices of (1) Absolute fit comprised of Goodness of Fit Index (GFI) and Root Mean Square of Error Approximation (RMSEA), (2) Incremental fit comprised of Comparative Fit Index (CFI), and (3) Parsimonious fit comprised of chi square/df [49]. The model testing for the relationship between domains was set at the significant level of $p<0.05$.

\section{Results}

Of the 1150 questionnaires distributed to 24 kindergartens, a total of 873 mothers returned the questionnaire (75.9\% response rate). Three children refused to be examined and were excluded while another 28 questionnaires were incomplete. As a result, a total of 842 complete mother-child dyads were included in the data analysis.

Table 1 shows the socio-demographic and clinical characteristics of the participants. More than half of the children were girls (52.3\%) and of Malay ethnicity. The mean age was $5.6(\mathrm{SD}=0.5)$ years. Most of the children attended private kindergartens while the majority of kindergartens were located in urban areas. Almost half of the mothers had secondary school education, and over two-fifths had a monthly income of MYR1500-3500 (moderate income level). More than two-thirds of the children had caries with a mean overall $\mathrm{dmft}$ score of 4.3 $(\mathrm{SD}=4.6)$.

Table 2 shows the summary of total ECOHIS, CIS, FIS, child dental anxiety $\left(\mathrm{MCDAS}_{\mathrm{f}}\right)$, and maternal dental
Table 1 Socio-demographic characteristics of the participants including clinical characteristics of children aged 5-6 years $(n=842)$

\begin{tabular}{|c|c|c|}
\hline & $\begin{array}{l}\text { Mother } \\
\text { n (\%) }\end{array}$ & $\begin{array}{l}\text { Child } \\
\text { n (\%) }\end{array}$ \\
\hline Mean age/year (SD) & $37.2(12.7)$ & $5.6(0.5)$ \\
\hline \multicolumn{3}{|l|}{ Age group/year } \\
\hline 5 & - & $363(43.1)$ \\
\hline 6 & & $479(56.9)$ \\
\hline \multicolumn{3}{|l|}{ Gender } \\
\hline Boy & - & $402(47.7)$ \\
\hline Girl & & $440(52.3)$ \\
\hline \multicolumn{3}{|l|}{ Ethnicity } \\
\hline Malay & $768(91.2)$ & $776(92.1)$ \\
\hline Chinese & $14(1.7)$ & $14(1.7)$ \\
\hline Indian & $29(3.4)$ & $31(3.7)$ \\
\hline Others & $31(3.7)$ & $21(2.5)$ \\
\hline \multicolumn{3}{|l|}{ Level of education ${ }^{\mathrm{a}}$} \\
\hline No formal schooling/primary school & $28(3.4)$ & - \\
\hline Secondary school & $415(49.3)$ & \\
\hline College or university & $382(45.4)$ & \\
\hline \multicolumn{3}{|l|}{ Monthly income (MYR) $)^{b}$} \\
\hline Low $<1500$ & $162(19.2)$ & - \\
\hline Moderate 1500-3500 & $347(41.2)$ & \\
\hline High $>3500$ & $318(37.8)$ & \\
\hline \multicolumn{3}{|l|}{ Location of kindergarten } \\
\hline Rural & - & $248(29.5)$ \\
\hline Urban & & $594(70.5)$ \\
\hline \multicolumn{3}{|l|}{ Type of kindergarten } \\
\hline Public/government & - & $310(36.8)$ \\
\hline Private & & $532(63.2)$ \\
\hline \multicolumn{3}{|l|}{ Caries status } \\
\hline Caries-free & - & $270(32.1)$ \\
\hline With caries & & $572(67.9)$ \\
\hline \multicolumn{3}{|l|}{ Caries experience } \\
\hline Mean dmft (SD) & - & $4.3(4.6)$ \\
\hline Mean dt (SD) & & $4.0(4.5)$ \\
\hline Mean mt (SD) & & $0.1(0.4)$ \\
\hline Mean ft (SD) & & $0.2(0.7)$ \\
\hline
\end{tabular}

MYR Malaysian Ringgit

a Missing values for level of education $=17(2 \%)$

b Missing values for monthly income $=15(1.8 \%)$

anxiety (MDAS) scores. The mean scores of total ECOHIS, CIS, and FIS subscales were quite low. The mean scores for all 6 domains of ECOHIS were skewed towards the minimum score range. The 6-item $\mathrm{MCDAS}_{\mathrm{f}}$ scores ranged from 6 to 30 with a mean score of $16.9(\mathrm{SD}=4.3)$. More than half of the children reported having high anxiety levels. For the mothers, the 5 -item MDAS scores ranged from 5 to 25 with a mean score of $11.8(\mathrm{SD}=4.5)$. 
Table 2 Summary data on total ECOHIS, the CIS, FIS, child dental anxiety $\left(\right.$ MCDAS $\left._{\mathrm{f}}\right)$, and maternal dental anxiety (MDAS) $(n=842)$

\begin{tabular}{|c|c|c|c|c|}
\hline & $\begin{array}{l}\text { Possible minimum and maximum } \\
\text { score range }\end{array}$ & Score range & Mean (SD) & Frequency (\%) \\
\hline ECOHIS (total) ${ }^{\mathrm{a}}$ & $13-52$ & $13-38$ & $17.7(4.9)$ & \\
\hline CIS & $9-36$ & $9-27$ & $12.6(3.7)$ & - \\
\hline FIS & $4-16$ & $4-20$ & $5.1(1.9)$ & \\
\hline \multicolumn{5}{|l|}{ ECOHIS domain: } \\
\hline Child symptoms (1 item) & $1-4$ & $1-4$ & $1.7(0.9)$ & \\
\hline Child function (4 items) & $4-16$ & $4-12$ & $5.3(1.7)$ & \\
\hline Child psychology (2 items) & $2-8$ & $2-8$ & $3.0(1.4)$ & - \\
\hline Child self-image (2 items) & $2-8$ & $2-8$ & $2.5(1.2)$ & \\
\hline Parent distress ( 2 items) $)^{a}$ & $2-8$ & $2-8$ & $2.9(1.5)$ & \\
\hline Family function (2 items) $)^{b}$ & $2-8$ & $2-8$ & $2.3(0.7)$ & \\
\hline Child dental anxiety $\left(\mathrm{MCDAS}_{\mathrm{f}}\right)$ & $6-30$ & $6-30$ & $16.9(4.3)$ & - \\
\hline \multicolumn{5}{|l|}{ Child dental anxiety $\left(\mathrm{MCDAS}_{\mathrm{f}}\right)$} \\
\hline Low/moderate & - & - & - & $388(46.1)$ \\
\hline High & & & & $454(53.9)$ \\
\hline Maternal dental anxiety (MDAS) & $5-25$ & $5-25$ & $11.8(4.5)$ & - \\
\hline \multicolumn{5}{|l|}{ Maternal dental anxiety (MDAS) } \\
\hline Low/moderate & - & - & - & $769(91.3)$ \\
\hline High & & & & $73(8.7)$ \\
\hline
\end{tabular}

${ }^{\mathrm{a}}$ Missing values $=14(1.4 \%)$

b Missing values $=3(0.4 \%)$

A large majority of the mothers had low or moderate dental anxiety.

Table 3 shows the overview of responses to the ECOHIS items and domains. More children were reported to have experienced an impact in the child symptoms domain (27.2\%). This was followed by the child psychology domain with "become irritable and frustrated" (23.3\%). This was followed by the child function domain with "difficulty in eating some foods" (15.6\%) and "difficulty in pronouncing any words" (14.7\%). This was followed by the child self-image domain. In the FIS subscale, parent distress was the more frequently affected domain with "parent felt guilty" (13.6\%) and "parent been upset" (13.3\%), followed by the family function domain.

Table 4 shows the results of Structural Model Impact of maternal dental anxiety and child dental anxiety on COHRQoL (total ECOHIS), CIS, and FIS $(n=842)$. Maternal dental anxiety and child dental caries (dmft) showed significant impact on COHRQoL, CIS, and FIS $(p<0.05)$. Maternal dental anxiety also showed significant impact on child dental caries $(p=0.014)$. However, child dental anxiety does not have any significant direct impact on COHRQoL, CIS, FIS, or child dental caries.

Figure 1 shows the Standardised Structural Model Impact of maternal and child's dental anxiety on COHRQoL. Children's OHRQoL was dependent on maternal dental anxiety and child's dental caries by $12.0 \%$. The items for each domain have factor loading ranging from 0.22 to 0.87 . Although some literature states that items with loading below 0.5 should be discarded from the model, they were maintained in this study as there was strong evidence that the items were important in this structural model [31]. Since all the items were retained in the model, this influenced the model fit indices (the model fitness almost approaching the cut off point; chisq/ $\mathrm{df}<5.0$, GFI $>0.90$, RMSEA $<0.10$, CFI $>0.90$ ). According to Browne and Cudeck [50], the values of RMSEA ranging from 0.08 to 0.10 are considered as a mediocre fit. Only RMSEA (RMSEA $=0.095$ ) fulfilled the model fit indices. The correlation between mother's dental anxiety and children's dental anxiety was very low $(r=0.03)$.

Table 5 shows the moderator test for the demographic influence on the maternal dental anxiety and COHRQoL relationship. Since there was a significant effect of maternal dental anxiety on COHRQoL in the Structural Equation Model, this study proceeded to investigate demographic factors as a moderator in this relationship. The demographic variables selected were mother's education level, household income, location of kindergarten, and type of kindergarten. The maternal dental anxiety-COHRQoL model was constraining with covariance which resulted in a chi square 
Table 3 Overview of responses to the ECOHIS items $(n=842)$

\begin{tabular}{|c|c|c|c|c|c|}
\hline Study variable & $\begin{array}{l}\text { Never } \\
\mathrm{n}(\%)\end{array}$ & $\begin{array}{l}\text { Hardly ever } \\
\text { n (\%) }\end{array}$ & $\begin{array}{l}\text { Occasionally } \\
\text { n (\%) }\end{array}$ & $\begin{array}{l}\text { Often } \\
\mathrm{n}(\%)\end{array}$ & $\begin{array}{l}\text { Very often } \\
\text { n (\%) }\end{array}$ \\
\hline \multicolumn{6}{|l|}{ Child symptoms (1 item) } \\
\hline Pain in the teeth, mouth or jaw & $456(54.2)$ & $157(18.6)$ & $216(25.7)$ & $11(1.3)$ & $2(0.2)$ \\
\hline \multicolumn{6}{|l|}{ Child function (4 items) } \\
\hline Had difficulty in drinking hot \& cold beverages & $682(81.0)$ & $79(9.4)$ & $76(9.0)$ & $5(0.6)$ & - \\
\hline Had difficulty in eating some Foods & $583(69.2)$ & $128(15.2)$ & $112(13.3)$ & $18(2.1)$ & $1(0.1)$ \\
\hline Had difficulty in pronouncing any words & $624(74.1)$ & $94(11.2)$ & $109(12.9)$ & $12(1.4)$ & $3(0.4)$ \\
\hline Missed school, day care & $815(96.8)$ & $16(1.9)$ & $10(1.2)$ & - & $1(0.1)$ \\
\hline \multicolumn{6}{|l|}{ Child psychology ( 2 items) } \\
\hline Had trouble sleeping & $652(77.4)$ & $81(9.6)$ & $94(11.2)$ & $15(1.8)$ & - \\
\hline Became irritable and frustrated & $511(60.7)$ & $135(16.0)$ & $168(20.0)$ & $24(2.9)$ & $4(0.5)$ \\
\hline \multicolumn{6}{|l|}{ Child self-image (2 items) } \\
\hline Avoided smiling or laughing & $687(81.6)$ & $78(9.3)$ & $73(8.7)$ & $4(0.5)$ & - \\
\hline Avoided talking & $700(83.1)$ & $60(7.1)$ & $79(9.4)$ & $3(0.4)$ & - \\
\hline \multicolumn{6}{|l|}{ Parent distress (2 items) } \\
\hline Been upset ${ }^{\mathrm{a}}$ & $610(72.4)$ & $120(14.3)$ & $81(9.6)$ & $14(1.7)$ & $5(0.6)$ \\
\hline Felt guilty ${ }^{a}$ & $567(67.3)$ & $161(19.1)$ & $76(9.0)$ & $18(2.1)$ & $8(1.0)$ \\
\hline \multicolumn{6}{|l|}{ Family function (2 items) } \\
\hline Taken time off & $762(90.5)$ & $44(5.2)$ & $31(3.7)$ & $1(0.1)$ & $1(0.1)$ \\
\hline Financial impact ${ }^{b}$ & $787(93.5)$ & $17(2.0)$ & $33(3.9)$ & $1(0.1)$ & $1(0.1)$ \\
\hline
\end{tabular}

a Missing values $=12(1.4 \%)$

b Missing values $=3(0.4 \%)$

Table 4 Path Analysis for Structural Model Impact of Mother's Dental Anxiety, Children's Dental Anxiety (Model 1), and Children's Dental Caries (Model 2) on COHRQoL, Child Impact Section (CIS) and Family Impact Section (FIS) [n=842]

\begin{tabular}{llrr}
\hline Relationship & Beta estimate & S.E & C.R value \\
\hline Mother's Dental Anxiety $\rightarrow$ COHRQOL & 0.14 & 0.03 & -5.02 \\
Children's Dental Anxiety $\rightarrow$ COHRQOL & 0.00 & 0.03 & 0.01 \\
Children's Dental Caries $\rightarrow$ COHRQOL & 0.04 & 0.01 & 0.02 \\
Mother's Dental Anxiety $\rightarrow$ CIS & 0.08 & 0.02 & -6.74 \\
Children's Dental Anxiety $\rightarrow$ CIS & 0.01 & 0.01 & -4.71 \\
Children's Dental Caries $\rightarrow$ CIS & 0.01 & 0.01 & -0.30 \\
Mother's Dental Anxiety $\rightarrow$ FIS & 0.001 & 0.001 \\
Children's Dental Anxiety $\rightarrow$ FIS & 0.01 & 0.01 & -3.23 \\
Children's Dental Caries $\rightarrow$ FIS & 0.01 & 0.01 & -3.18 \\
\hline
\end{tabular}

difference above 3.84. These results show that all the demographic variables selected can act as moderators in the maternal dental anxiety-COHRQoL model.

Table 6 shows the effect of demographics on the maternal dental anxiety and COHRQoL relationship. All the levels in demographic groups were significant in the model $(p<0.05)$. Maternal dental anxiety with high education level shows better COHRQoL (standardized beta estimate $=0.29, p<0.001)$. Similarly, maternal dental anxiety with high income level shows better COHRQoL (standardized beta estimate $=0.23$, $p<0.001)$.

\section{Discussion}

This study investigated the impact of maternal and child dental anxiety on the OHRQoL of 5-6-year-old preschool children. The role of demographic factors and child's dental caries experience with the COHRQoL were also evaluated. Structural equation models were designed to inspect the relationships between maternal 


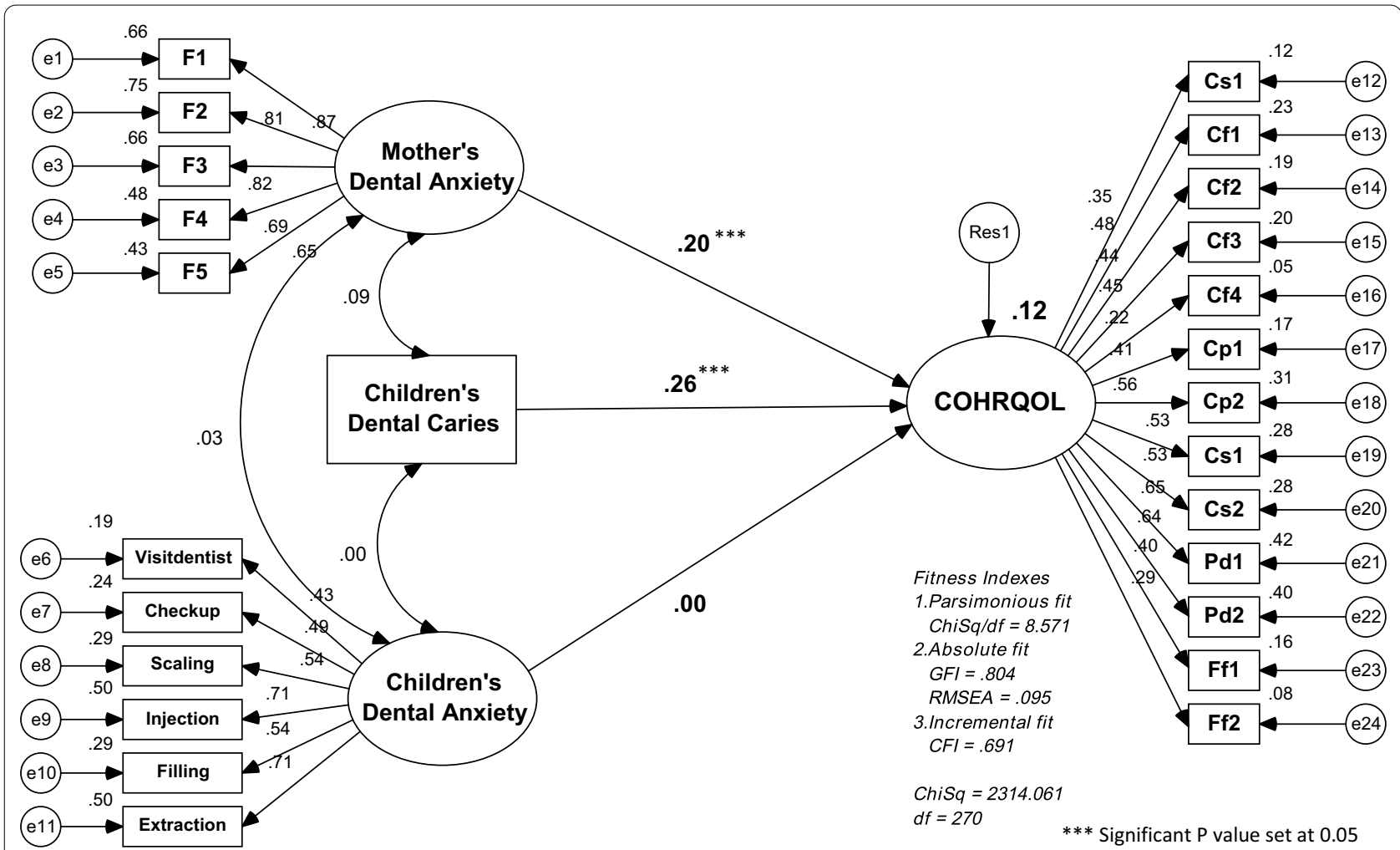

Fig. 1 Standardized structural model impact of Mother's Dental Anxiety, Children's Dental Anxiety, and Children's Dental Caries on COHRQoL $(n=842)$

Table 5 Demographic effect on the Maternal Dental Anxiety and COHRQoL relationship (Model 3) $(n=842)$

\begin{tabular}{|c|c|c|c|}
\hline \multirow[t]{2}{*}{ Variable tested } & \multicolumn{3}{|l|}{$\mathrm{X}^{2}$ value } \\
\hline & $\begin{array}{l}\text { Constrained } \\
\text { model (A) }\end{array}$ & $\begin{array}{l}\text { Unconstrained } \\
\text { model (B) }\end{array}$ & Difference $(A-B)$ \\
\hline \multicolumn{4}{|l|}{ Education } \\
\hline Low & 1172.98 & 901.49 & 271.49 \\
\hline High & 1204.81 & 909.54 & 295.27 \\
\hline \multicolumn{4}{|l|}{ Income } \\
\hline $\begin{array}{l}\text { Low to moder- } \\
\text { ate }\end{array}$ & 1245.52 & 942.86 & 302.66 \\
\hline High & 1216.55 & 949.61 & 266.94 \\
\hline \multicolumn{4}{|l|}{ Location } \\
\hline Rural & 798.59 & 650.49 & 148.10 \\
\hline Urban & 1663.31 & 1201.90 & 461.41 \\
\hline \multicolumn{4}{|l|}{ Type } \\
\hline $\begin{array}{l}\text { Government/ } \\
\text { public }\end{array}$ & 756.81 & 556.21 & 200.60 \\
\hline Private & 1659.44 & 1233.40 & 426.04 \\
\hline
\end{tabular}

Constrained model; $\mathrm{df}=135$, Unconstrained model; $\mathrm{df}=134$

Education Level; Low level comprises of No formal education, Primary school and Secondary school, High level comprises of College and university

Income Level; Low to moderate (income less than MYR3500), High (income MYR3500 and above)
Table 6 Demographic effect on Maternal Dental Anxiety and COHRQoL relationship (Model 3$)(n=842)$

\begin{tabular}{lllr}
\hline Demographic effect & Standardised beta estimate & $\boldsymbol{p}$ value & \\
\hline Education & Low & 0.13 & 0.026 \\
& High & 0.29 & $<0.001$ \\
Income & Low to moderate & 0.19 & $<0.001$ \\
& High & 0.23 & $<0.001$ \\
Location & Rural & 0.22 & 0.004 \\
& Urban & 0.23 & $<0.001$ \\
Type & Government/public & 0.19 & 0.006 \\
& Private & 0.26 & $<0.001$ \\
\hline
\end{tabular}

dental anxiety, child dental anxiety, child dental caries, and COHRQoL and its domains. In addition, the role of demographic factors as moderators was also determined.

Mothers are the main caregivers responsible for childrearing and transmitting health related behaviours to their children [18, 29]. A large sample of preschool children where the majority of parents were young mothers of Malay ethnicity aged less than 40 years participated in this study. The sample demographic background was almost similar to the Malaysian population strata [51]. 
Also, there was a slight discrepancy between the ethnicity of mothers and children, the reason being the ethnicity of the children followed that of the father.

Past studies had reported that higher paternal or maternal dental anxiety was associated with poorer OHRQoL of their preschool children $[17,29,52]$. This study also found that maternal dental anxiety and child dental caries (dmft) showed significant impact on COHRQoL (total ECOHIS). Higher MDAS scores would highly influence how the mother perceives the impact of child oral health on the total ECOHIS scores. In other words, mothers who are more anxious would "rate" their children's OHRQoL poorly. Although some of the items for each domain of the ECOHIS have low factor loadings (below 0.5 ), these 13 items of the ECOHIS were retained in the model as this could be due to the very low mean scores of total ECOHIS subscales in this sample. The mean scores for all 6 domains of ECOHIS were also skewed towards the minimum score range. Additionally, for the category of impact response options 'never' or 'hardly ever' were categorised into 'no impact.' The scores for 'no impact' ranged from $72.8 \%$ (child symptom) to $98.7 \%$ (missed school or day care). The variation within these items would be attenuated and hence, unlikely to produce a good model fit. Future studies using qualitative methods are recommended to review the items as social and cultural variations exist within this diverse population $[6$, 53].

Nevertheless, these findings may still be of importance because the impacts would directly influence the child's daily activities, psychosocial well-being, as well as the family's general functioning. Furthermore, the magnitude of association will tend to be greater as the mother's dental anxiety level gets higher.

In this study, anxious mothers were significantly associated with poorer COHRQoL in both the CIS and FIS domains. However, these findings were different from that of Goettems et al. [17]. The latter reported that the impact of maternal dental anxiety was mainly on the parent distress domain. This difference could be due to the geographical and cultural variations between the samples in the two studies. In Goettems' study, only maternal dental anxiety was assessed and the ECOHIS was assessed with children aged 2-5 years. Furthermore, the four-item Corah's DAS scale to assess maternal dental anxiety was used in that study [17].

In addition, child's dental caries was found to be associated with maternal dental anxiety and COHRQoL. The children's overall dmft score was 4.3 of which $93.0 \%$ comprised of decayed teeth. This finding was not unexpected as children with decayed and missing teeth tend to complain of pain as well as difficulties in eating and pronouncing words. The mean $\mathrm{dmft}$ score in this study was almost similar to the mean $\mathrm{dmft}$ score of 4.6 among 5 year-old preschool children in a recent national oral health survey [54]. Other studies also found a similar finding where untreated dental caries had affected the quality of life of the children [19, 22]. Buldur and Guvendi [18] found an indirect relationship between parental dental anxiety, dental caries, and COHRQoL. However, Low et al., [55] reported that children may not complain of pain from decayed teeth but may be affected by other impacts related to oral function.

In the path analysis model for the influence of demographic factors on maternal dental anxiety and COHRQoL, it was found that all four factors acted as moderators to the relationship. These four factors include education, family income, location, and type of kindergarten. Mothers with higher education and family income have better perception on the COHRQoL. It could be that mothers with different education levels have different perceptions of how their children's oral health has impacted their daily life and well-being. The reason could be that families with higher incomes would be less likely to suffer financial impact when they bring their child to a dentist for dental treatment than families with lower incomes. Also, families with higher incomes tend to have children with better oral health [56]. Subsequently, their parents would be less likely to take time off work because of their child's dental problems. These findings were also supported by similar studies elsewhere $[17-19,57,58]$. Sending a child to private kindergartens which are mainly situated in urban areas is also related to higher education and income. Similarly, an earlier local study also found that urban-rural dichotomy also acted as a moderator for the relationship between dental caries and dental fear among adolescents [59].

In contrast, we found that child dental anxiety does not have any significant direct impact on COHRQoL, CIS, FIS, or child dental caries. A possible reason for this could be that the decision to bring the child to visit the dentist for a check-up or preventive care is decided mainly by the mother or guardian regardless of the child's dental anxiety level. In addition, the kindergartens in Malaysia receive an annual visit from the school dental team where a dental therapist will conduct an oral examination, do preventive treatment, and deliver oral health education to the children. As a result, the children would still benefit from the preventive care and oral health education given by the school dental team regardless of whether they were dentally anxious or not.

A high proportion of the preschool children in this study reported high anxiety levels. In contrast, the majority of the mothers reported low or moderate dental anxiety levels. Only $9.0 \%$ of mothers had high anxiety levels. The correlation between mother's dental anxiety and 
children's dental anxiety was found to be very low in this study. Few studies had reported similar findings but the majority of studies confirmed a relationship between maternal and child dental anxiety especially in children aged 8 years and below [17, 18, 25, 29, 52].

The strength of this study is employing SEM and determining the moderator effect on the relationship between maternal dental anxiety and COHRQoL. However, the development and testing of a complex multi-model needs to be explored further to include other related variables affecting this relationship.

This study had several limitations. First, the use of the Malay-ECOHIS relied on the mothers' perceptions of their child's oral health and its impacts on the child and family. As a result, different mothers had different perceptions of their child's oral health and these might be influenced, among others, by the mother-child relationship, mother's personalities, family dynamics, and the socio-environment of the family. It was probable that mothers with dental anxiety would be more likely to rate their COHRQoL poorly than mothers with no dental anxiety. This possibility could be true especially when no association was found between child dental anxiety and COHRQoL in this study. Future studies should consider the validity of proxy reports on the COHRQoL by mothers including undertaking a qualitative study involving both the mothers and children. Cohort studies to address the limitations of a cross-sectional study design in inferring causation between maternal dental anxiety and COHRQoL are also recommended [60]. Second, paternal dental anxiety was not assessed in this study. This was because in Malaysian culture, mothers play an important role in the upbringing of the child and tend to be closer to the child than fathers. Therefore, mothers would be regarded as a better proxy than fathers to assess COHRQoL. Future studies should also look into parental dental anxiety and its association with COHRQoL.

\section{Conclusions}

Maternal dental anxiety and child's dental caries experience have significantly impacted the COHRQoL, the CIS, and FIS domains of 5-6-year-old preschool children. In addition, demographic factors such as education, income, urban/rural location, and kindergarten type acted as moderators that modify the strengths of the relationship between maternal dental anxiety and COHRQoL.

\footnotetext{
Abbreviations

CIS: Child impacts section; COHRQoL: Child's oral health-related quality of life; FIS: Family impacts section; Malay-ECOHIS: Malay version of Early Childhood Oral Health Impact Scale; Malay-MCDAS: Malay version of Modified Child Dental Anxiety Scale faces version; Malay-MDAS: Malay version of Modified Dental Anxiety Scale; OHRQoL: Oral health-related quality of life.
}

\section{Acknowledgements}

We would like to thank the mothers, teachers, and preschool children who helped and participated in this study. Special thanks also to Madam Siti Nur Farliza for her statistical support and advice.

\section{Authors' contributions}

RE contributed to the design of the study, acquisition of data, analysis and interpretation of data, and drafting of the manuscript. MJ contributed to the study design, acquisition of data, analysis and interpretation of data, and drafting of the manuscript. ZYMY contributed to the acquisition of data, analysis and interpretation of data, and drafting of the manuscript. All authors read and approved the final manuscript.

\section{Funding}

This research was funded by the University of Malaya Impact-Oriented Interdisciplinary Research Grant (No: IIRG 035A-2019).

\section{Availability of data and materials}

The datasets used and/or analysed during the current study are available from the corresponding author on reasonable request.

\section{Ethics approval and consent to participate}

The study was approved by the Medical Ethics Committee, Faculty of Dentistry, University of Malaya [Reference: DF OP0809/0030(L)]. Permission to conduct the study was obtained from the Ministry of Education, Selangor State Education Department, kindergarten teachers, and parents of the children. Informed written consent was obtained from participants prior to data collection.

\section{Consent for publication}

Not applicable.

\section{Competing interests}

The authors declare that they have no competing interests.

\section{Author details}

${ }^{1}$ Department of Dental Public Health, Faculty of Dentistry, MAHSA University, Bandar Saujana Putra, 42610 Jenjarom, Selangor, Malaysia. ${ }^{2}$ Department of Community Oral Health and Clinical Prevention, Faculty of Dentistry, University of Malaya, 50603 Kuala Lumpur, Malaysia. ${ }^{3}$ Community Oral Health Research Group, Faculty of Dentistry, University of Malaya, 50603 Kuala Lumpur, Malaysia.

Received: 12 September 2019 Accepted: 16 September 2020 Published online: 29 September 2020

\section{References}

1. Milgrom P, Mancl L, King B, Weinstein P. Origins of childhood dental fear. Behav Res Ther. 1995;33:313-9.

2. Klingberg G, Broberg AG. Dental fear/anxiety and dental behaviour management problems in children and adolescents: a review of prevalence and concomitant psychological factors. Int J Paediatr Dent. 2007; 17:391-406

3. Cianetti S, Lombardo G, Lupatelli E, Pagano S, Abraha I, Montedori A, Caruso S, Gatto R, De Giorgio S, Salvato R. Dental fear/anxiety among children and adolescents. A systematic review. Eur J Paediatr Dent. 2017;18:121-30.

4. Hmud R, Walsh L. Dental anxiety: causes, complications and management approaches. J Minim Interv Dent. 2009;2:67-78.

5. Costa FS, Cademartori MG, Silva MF, Nascimento GG, Shqair AQ, Pinheiro RT, Demarco FF, Goettems ML. Anxiety symptoms have a direct effect on oral health perception in young women. Qual Life Res. 2018;27:1583-8.

6. Esa R, Savithri $\vee$, Humphris $G$, Freeman R. The relationship between dental anxiety and dental decay experience in antenatal mothers. Eur J Oral Sci. 2010;118:59-65.

7. Siow YY. Oral health status and perceived barriers to utilization of oral healthcare among antenatal mothers. Dissertation. University of Malaya, Kuala Lumpur; 2000. 
8. Smith TA, Heaton $L$. Fear of dental care. Are we making any progress. J Am Dent Assoc. 2003;134:1101-8.

9. Berggren U, Pierce CJ, Eli I. Characteristics of adult dentally fearful individuals. A cross-cultural study. Eur J Oral Sci. 2000;108:268-74.

10. Armfield JM, Stewart JF, Spencer AJ. The vicious cycle of dental fear: exploring the interplay between oral health, service utilization and dental fear. BMC Oral Health. 2007;7:1-15.

11. Gavic L, Tadin A, Mihanovic I, Gorseta K, Cigic L. The role of parental anxiety, depression, and psychological stress level on the development of early-childhood caries in children. Int J Paediatr Dent. 2018;28:616-23.

12. Delgado-Angulo EK, Sabbah W, Suominen AL, Vehkalahti MM, Knuuttila M, Partonen T, Nordblad A, Sheiham A, Watt RG, Tsakos G. The association of depression and anxiety with dental caries and periodontal disease among Finnish adults. Community Dent Oral Epidemiol. 2015;43:540-9.

13. Goettems ML, Nascimento GG, Peres MA, Santos IS, Matijasevich A, Barros AJD, Peres KG, Demarco FF. Influence of maternal characteristics and caregiving behaviours on children's caries experience: an intergenerational approach. Community Dent Oral Epidemiol. 2018:46:435-41.

14. Buldur B. Pathways between parental and individual determinants of dental caries and dental visit behaviours among children: validation of a new conceptual model. Community Dent Oral Epidemiol. 2020;48:280-7.

15. Porritt J, Morgan A, Rodd H, Gupta E, Gilchrist F, Baker S, Newton T, Creswell C, Williams C, Marshman Z. Development and evaluation of the children's experiences of dental anxiety measure. Int J Paediatr Dent. 2018;28:140-51.

16. Vermaire $\mathrm{JH}$, de Jongh $\mathrm{A}$, Aartman $\mathrm{IH}$. Dental anxiety and quality of life: the effect of dental treatment. Community Dent Oral Epidemiol. 2008;36:409-16.

17. Goettems ML, Ardenghi TM, Romano AR, Demarco FF, Torriani DD. Influence of maternal dental anxiety on oral health-related quality of life of preschool children. Qual Life Res. 2011:20:951-9.

18. Buldur B, Güvendi ON. Conceptual modelling of the factors affecting oral health-related quality of life in children: a path analysis. Int J of Paediatr Dent. 2020;30:181-92.

19. Abanto J, Carvalho TS, Mendes FM, Wanderley MT, Bönecker M, Raggio DP. Impact of oral diseases and disorders on oral health-related quality of life of preschool children. Community Dent Oral Epidemiol. 2011:39:105-14

20. Slade GD. Measuring oral health and quality of life. Chapel Hill: University of North Carolina; 1997.

21. Sheiham A. Dental caries affects body weight, growth and quality of life in pre-school children. Br Dent J. 2006;201:625-6.

22. Filstrup SL, Briskie D, da Fonseca M, Lawrence L, Wandera A, Inglehart MR. Early childhood caries and quality of life: child and parent perspectives. Pediatr Dent. 2003;25:431-40.

23. Petersen PE. The World Oral Health Report 2003: continuous improvement of oral health in the 21st century-the approach of the WHO Global Oral Health Programme. Community Dent Oral Epidemiol. 2003;31 (Suppl 1):3-23.

24. Gift HC, Reisine ST, Larach DC. The social impact of dental problems and visits. Am J Public Health. 1992;82:1663-8.

25. Themessl-Huber M, Freeman R, Humphris G, MacGillivray S, Terzi N. Empirical evidence of the relationship between parental and child dental fear: a structured review and meta-analysis. Int J Paediatr Dent. 2010;20:83-101.

26. Goettems ML, Ardenghi TM, Romano AR, Demarco FF, Torriani DD. Influence of maternal dental anxiety on the child's dental caries experience. Caries Res. 2012:46:3-8.

27. Buldur B, Armfield JM. Development of the Turkish version of the Index of Dental Anxiety and Fear (IDAF-4C+): dental anxiety and concomitant factors in pediatric dental patients. J Clin Pediatr Dent. 2018;42:279-86.

28. Murali K, Shanmugam S. Influence of mothers' dental anxiety and perception of child's OHRQoL towards utilization of dental services-a questionnaire study. J Indian Assoc Pubic Health Dent. 2017a;15:17-22.

29. Costa FDS, Azevedo MS, Ardenghi TM, Pinheiro RT, Demarco FF, Goettems ML. Do maternal depression and anxiety influence children's oral healthrelated quality of life? Community Dent Oral Epidemiol. 2017:45:398-406.

30. Dahlander A, Soares F, Grindefjord M, Dahllöf G. Factors associated with dental fear and anxiety in children aged 7 to 9 years. Dentistry $\mathrm{J}$. 2019;7:68.
31. Hashim AN, Yusof ZYM, Esa R. The Malay version of the Early Childhood Oral Health Impact Scale (Malay-ECOHIS)_assessing validity and reliability. Health Qual Life Outcomes. 2015;13:190.

32. Sitheeque M, Massoud M, Yahya S, Humphris G. Validation of the Malay version of the Modified Dental Anxiety Scale and the prevalence of dental anxiety in a Malaysian population. J Investig Clin Dent. 2015;6:313-20.

33. Esa R, Hashim NA, Ayob Y, Yusof ZY. Psychometric properties of the faces version of the Malay-modified child dental anxiety scale. BMC Oral Health. 2015:15:28.

34. Department of Statistics. Household income and basic amenities survey 2009. Putrajaya, Malaysia: Department of Statistics; 2010.

35. Humphris GM, Morrison T, Lindsay SJ. The Modified Dental Anxiety Scale: validation and United Kingdom norms. Community Dent Health. 1995:12:143-50.

36. Humphris GM, Freeman R, Campbell J, Tuutti H, D'Souza V. Further evidence for the reliability and validity of the Modified Dental Anxiety Scale. Int Dent J. 2000;50:367-70.

37. Howard KE, Freeman R. Reliability and validity of a faces version of the Modified Child Dental Anxiety Scale. Int J Paediatr Dent. 2007;17:281-8.

38. Wong HM, Humphris GM, Lee GT. Preliminary validation and reliability of the Modified Child Dental Anxiety Scale. Psychol Rep. 1998;83:1179-86.

39. Christophorou S, Lee GTR, Humphris GM. The reliability and validity of the Modified Child Dental Anxiety Scale: a study of Greek Cypriot school children. Eur J Paediatr Dent. 2000;1:75-81.

40. Pahel B, Rozier RG, Slade G. Parental perceptions of children's oral health: The Early Childhood Oral Health Impact Scale (ECOHIS). Health Qual Life Outcomes. 2007:5:6.

41. Cesar J, de Moraes AB, Milgrom P, Kleinknecht RA. Cross validation of a Brazilian version of the Dental Fear Survey. Community Dent Oral Epidemiol. 1993;21:148-50.

42. Coolidge T, Arapostathis KN, Emmanouil D, Dabarakis N, Patrikiou A, Economides N, Kotsanos N. Psychometric properties of Greek versions of the Modified Corah Dental Anxiety Scale (MDAS) and the Dental Fear Survey (DFS). BMC Oral Health. 2008;8:29.

43. Jaakkola S, Rautava P, Alanen P, Aromaa M, Pienihakkinen K, Raiha H, Vahlberg T, Mattila ML, Sillanpaa M. Dental fear: one single clinical question for measurement. Open Dent J. 2009;3:161-6.

44. Yoshida T, Milgrom P, Mori Y, Nakai Y, Kaji M, Shimono T, Donaldson AN. Reliability and cross-cultural validity of a Japanese version of the Dental Fear Survey. BMC Oral Health. 2009;9:17.

45. Lueken U, Hoyer J, Siegert J, Gloster AT, Wittchen HU. Symptom provocation in dental anxiety using cross-phobic video stimulation. Eur J Oral Sci. 2011;119:61-8

46. Sirin $Y$, Humphris $G$, Sencan $S$, Firat $D$. What is the most fearful intervention in ambulatory oral surgery? Analysis of an outpatient clinic. Int J Oral Maxillofac Surg. 2012;41:1284-90.

47. World Health Organisation. Oral health surveys: basic methods. 5th ed. Geneva: World Health Organisation; 2013.

48. Muthen BO, Satorra A. Complex sample data in structural equation modeling. Sociol Methodol. 1995;25:267-316.

49. Kline RB. Principles and practice of structure equation modelling. 4th ed. New York: The Guildford Press; 2015.

50. Browne MW, Cudeck R. Alternative ways of assessing model fit. In: Bollen KA, Long JS, editors. Testing structural equation models Newbury Park. CA: Sage; 1993.

51. DOSM. Current population estimates, Malaysia, 2016-2017. Kuala Lumpur: Department of Statistics Malaysia; 2017.

52. Murali K, Shanmugam S. Influence of Mothers' Dental Anxiety and Perception of Child's OHRQoL towards utilization of dental services-a questionnaire study. J Indian Assoc Public Health Dent. 2017b;15:17-22.

53. Helman CG. Culture, health and illness. 5th ed. UK: Hodder Arnold; 2007.

54. Che Salleh N, Yaw SL, Abd Muttalib K, AbRahman J. National oral health survey of preschool children (NOHPS). Vol. 1: Oral health status and caries treatment needs of 5-year-old children. Putrajaya: The Oral Health Division, Ministry of Health Malaysia; 2017.

55. Low W, Tan S, Schwartz S. The effect of severe caries on the quality of life in young children. Pediatr Dent. 1999;21:325-6.

56. Do LG, Spencer AJ, Slade GD, Ha DH, Roberts-Thomson KF, Liu P. Trend of income-related inequality of child oral health in Australia. J Dent Res. 2010:89:959-64. 
57. Locker D. Disparities in oral health-related quality of life in a population of Canadian children. Community Dent Oral Epidemiol. 2007;35:348-56.

58. Tsakos G, Sheiham A, lliffe S, Kharicha K, Harari D, Swift CG, Gillman G, Stuck AE. The impact of educational level on oral health-related quality of life in older people in London. Eur J Oral Sci. 2009;117:286-92.

59. Esa R, Ong AL, Humphris G, Freeman R. The relationship of dental caries and dental fear in Malaysian adolescents: a latent variable approach. BMC Oral Health. 2014;14:19.
60. Thomson WM, Broadbent JM, Locker D, Poulton R. Trajectories of dental anxiety in a birth cohort. Community Dent Oral Epidemiol. 2009;37:209-19.

\section{Publisher's Note}

Springer Nature remains neutral with regard to jurisdictional claims in published maps and institutional affiliations.
Ready to submit your research? Choose BMC and benefit from:

- fast, convenient online submission

- thorough peer review by experienced researchers in your field

- rapid publication on acceptance

- support for research data, including large and complex data types

- gold Open Access which fosters wider collaboration and increased citations

- maximum visibility for your research: over $100 \mathrm{M}$ website views per year

At BMC, research is always in progress.

Learn more biomedcentral.com/submissions 